\title{
Monitoring of Particulate Matter and Gaseous Pollutant in Aurangabad City
}

\author{
Gajanan Shelke ${ }^{1}$, Dr.Mohammed Sadeque ${ }^{2}$ \\ ${ }^{1}$ Post Graduate Student Environmental Engg., Jawaharlal Nehru Engineering College, Aurangabad. \\ ${ }^{2}$ Associate Professor, Dept. of Civil Engg., Jawaharlal Nehru Engineering College, Aurangabad.
}

\begin{abstract}
Concentration of gaseous pollutant and particulate matter are the major cause of respiratory disease and deaths. The dust pollution is serious matter almost in all cities of Maharashtra. This paper deals with the results of ambient monitoring of Aurangabad city for particulate matter, sulphur dioxide and nitrogen dioxide. The sulphur dioxide concentration is measured by Modified West and Geake Method whereas nitrogen dioxide is measured by Modified Jacob and Hochheiser method. The results shows a very high concentration of particulate matter, however sulphur dioxide and nitrogen dioxide were within the permissible limits.
\end{abstract}

Keywords: Pollution, particulate matter, gaseous pollutant, human health.

\section{Introduction}

Air, that human breath is mixture of gases and small solid and liquid particles. On an average a person breathes 22,000 times a day and take in about $24 \mathrm{~kg}$ of air in the process to sustain the requirement of oxygen. Air pollution has three main sources from human activities; stationary mobile and indoor. Air pollution occur when air contains substance in quantities that could harm the comfort or health of human and animals, or could called air pollutant and can be either particles, liquids or gaseous in nature [1]. The air pollutants can be classified as primary or secondary pollutants. The primary air pollutants are harmful chemicals which directly enter the air due to natural events of human activities. A secondary air pollutant is a harmful chemical produced in the air due to chemical reaction between two or more components. That is primary pollutant combines with some component of the atmosphere to produce a secondary pollutant [2]. Among the most common and poisonous air pollutants are sulphur dioxide $\left(\mathrm{SO}_{2}\right)$, formed when fossil fuels such as coal, gas and oil are used for power generation; suspended particulate matter (SPM), solid and liquid particles emitted from numerous man -made and natural sources such as industrial dust, volcanic eruptions and diesel-powered vehicles; and nitrogen oxides (NOx), from natural sources such as lightning, fires [3]. Particulate matter (PM) is the generic term used for a type of air pollutants, consisting of complex and varying mixtures of particles suspended in the breathing air, which vary in size and composition, and are produced by a wide variety of natural and anthropogenic activities. Major sources of particulate pollution are factories, power plants, refuse incinerators, motor vehicles, construction activity, fires, and natural windblown dust. For ambient air quality monitoring particle size with aerodynamic diameter smaller than $2.5 \mathrm{~mm}\left(\mathrm{PM}_{2.5}\right)$ and $10 \mathrm{~mm}\left(\mathrm{PM}_{10}\right)$ are taken into consideration. The size of the particles varies $\left(\mathrm{PM}_{2.5}\right.$ and $\mathrm{PM}_{10}$ for aerodynamic diameter smaller than $2.5 \mathrm{~mm}$ and $10 \mathrm{~mm}$ respectively) [4]. Nitrogen dioxide and related nitrogen oxides (NOx) are produced when fuel is burned. These compounds contribute to ozone formation and are a health problem themselves. The effect of NOx exposure on the respiratory system is similar to that of ozone and sulphur dioxide. Nitrogen oxides are byproducts of fuel combustion and contribute to the formation of ground-level ozone. Health effects include coughing, shortness of breath, and decreased lung function [5]. A sulphur dioxide is a primary air pollutant and its source is human activities and sometimes even natural events are responsible for it. As a result of chemical reaction of primary air pollutants, secondary air pollutants like sulphuric acid are produced in the atmosphere [6]. All these particulate matter and gaseous pollutant has adverse effect on environment and human health .Worldwide epidemiological studies show a consistent increase in cardiac and respiratory morbidity and mortality from exposure to particulate matter(PM) [7].PM is a key ingredient of polluted air and its estimated to killed more than 500,000 people each year [8].Each $10 \mu \mathrm{g} / \mathrm{m}^{3}$ elevation in fine particulate air pollution has been associated with approximately with 4,6 and $8 \%$ increased risk of all cause, cardio pulmonary and lung cancer mortality respectively [9].In December 1952, a dense smog containing sulphur dioxide and smoke particulate descended upon London, resulting in more than 3,000 excess deaths oven 3 weeks and as many as 12,000 through February 1953 [10].Children are particularly sensitive as their lungs as well as immune system are not completely developed when compared to adult one [11].To prevent this staggering loss of life we must understand the characteristics of toxic particles and gain insight into how these characteristics are related to adverse health effect [12].

Since most of the study the pollution studies in India focused on megacities, as smaller cities were generally taken as clean. This study was undertaken to determine the status of particulate matter $\left(\mathrm{PM}_{10}\right)$ and gaseous 
pollutant $\left(\mathrm{SO}_{2}\right.$ and $\left.\mathrm{NO}_{2}\right)$ due to vehicular traffic, industrial, construction and demolition, at different location of Aurangabad city. Aurangabad is developing city of Maharashtra state in India, surrounded by four industrial areas. This project is taken into consideration as very few studies has been carried out in past.

\section{Materials and Methods}

\subsection{Study area}

Aurangabad is named after the Mughal Emperor Aurangzeb. The city is a tourism hub, surrounded by many historical monument. Aurangabad is titled "The city of Gates" and was declared "Tourism Capital of Maharashtra" By population it is 5th largest city in Maharashtra after Mumbai, Pune, Nagpur and Nashik. Aurangabad is emerging as a prominent location for IT and manufacturing as it has many colleges and universities. The city is situated at a latitude of $19^{\circ} 53^{\prime} 59^{\prime \prime}$ North and longitude $75^{\circ} 20^{\prime} 59^{\prime \prime}$ East. Aurangabad's area is about $138 \mathrm{~km}^{2}$. The climate of Marathwada region is generally hot and dry. Annual mean temperatures in Aurangabad range from 17 to $33^{\circ} \mathrm{C}$. Most of the rainfall occurs in the monsoon season from June to September. The relative humidity is extremely low in this region for a major part of the year and ranges between 35 to $50 \%$, while it is the highest (85\%) during monsoon. Population of Aurangabad according to provisional report Census Board of India is 1,175,116. The number of male and female are 6,09,206 and 5,65,910 respectively. The city has large number of industrial units i.e. small, medium and large-scale. as about 1020 and almost 35,000 workers find their employment in these units[13]. Study area of Aurangabad with different sampling locations according to their longitudes are shown in Figure 1.

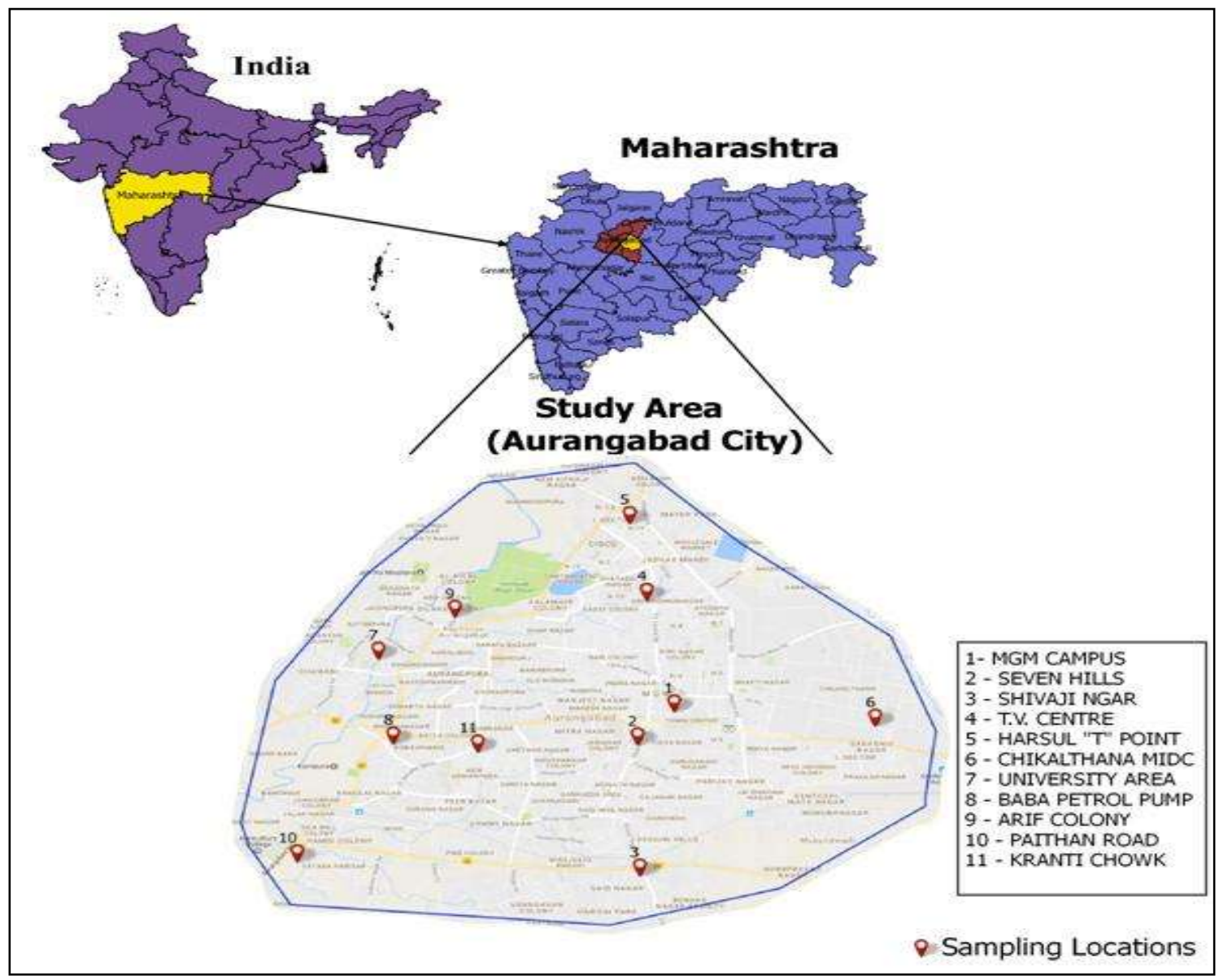

Figure No. 1- Map Showing Sampling Locations

For the study the samples were collected from different eleven locations in Aurangabad during May,2016June,2016. The sample collected for 24 hour. Whatman filter papers are used for sampling of $\mathrm{PM}_{10}$ with Respirable Dust Sampler (Model-APM460DXNL,Envirotech,New Delhi). For sampling of $\mathrm{NO}_{2}$ and $\mathrm{SO}_{2}$ dust sampler is attached with gas analyzer (Model-APM411TE, Envirotech, New Delhi). Humidity is taken into consideration during sampling period. Normally the sampler was kept on height ranging from $3 \mathrm{~m}$ to $6 \mathrm{~m}$. For the further analysis standard methods given by Central Pollution Control Board of India (CPCB) is adopted. Sampling sites are chosen according to population, land use pattern and traffic densities shown in Table 1. 
Table 1: Sampling Locations

\begin{tabular}{|c|c|c|c|c|}
\hline SR.NO & $\begin{array}{l}\text { Sampling } \\
\text { Location }\end{array}$ & Description & $\begin{array}{l}\text { Traffic } \\
\text { Density }\end{array}$ & Land Use pattern \\
\hline 1 & $\begin{array}{l}\text { MGM } \\
\text { Institutional } \\
\text { Campus }\end{array}$ & $\begin{array}{l}\text { Educational campus with } 9000 \text { students and } 1000 \text { faculties. Also } \\
\text { consists of Hospital Area. }\end{array}$ & Medium & Institutional \\
\hline 2 & Shivaji Nagar & $\begin{array}{l}\text { Densely polluted residential area with market. In the evening traffic } \\
\text { increases. }\end{array}$ & High & $\begin{array}{l}\text { Residential cum } \\
\text { commercial }\end{array}$ \\
\hline 3 & Sven Hills & $\begin{array}{l}\text { On Jalna road near to flyover, surrounded by commercial complex. } \\
\text { In the evening traffic increases. }\end{array}$ & High & Commercial \\
\hline 4 & T.V Centre & $\begin{array}{c}\text { Near to SP office. Pedestrian movement is more. Narrow road width. } \\
\text { In the evening traffic increases. }\end{array}$ & High & $\begin{array}{l}\text { Residential cum } \\
\text { commercial }\end{array}$ \\
\hline 5 & $\begin{array}{c}\text { Harsul } \\
\text { T-point }\end{array}$ & $\begin{array}{c}\text { City outskirts with roadway and state transport buses movement. } \\
\text { Heavy vehicles traffic is more. }\end{array}$ & High & $\begin{array}{l}\text { Residential cum } \\
\text { commercial }\end{array}$ \\
\hline 6 & $\begin{array}{l}\text { Chikalthana } \\
\text { MIDC }\end{array}$ & Industrial area with most of the units are functioning. & Medium & Industrial area \\
\hline 7 & University Area & $\begin{array}{l}\text { Oldest area of city with number of institutional centers, tourist place } \\
\text { like Bibika Makabara. }\end{array}$ & Medium & $\begin{array}{l}\text { Residential cum } \\
\text { Institutional }\end{array}$ \\
\hline 8 & $\begin{array}{l}\text { Baba Petrol } \\
\text { Pump }\end{array}$ & $\begin{array}{l}\text { From baba petrol pump roads deflects toward Pune, Nashik. Border } \\
\text { of city with high numbers of heavy vehicles. In the evening traffic } \\
\text { increases. }\end{array}$ & High & Commercial \\
\hline 9 & Arif colony & On high elevation other than all location. & Medium & Residential \\
\hline 10 & Paithan Road & $\begin{array}{c}\text { City outskirts where vehicles can bypass the city. Heavy truck and } \\
\text { private vehicles traffic. }\end{array}$ & High & $\begin{array}{l}\text { Residential cum } \\
\text { commercial }\end{array}$ \\
\hline 11 & Kranti Chowk & $\begin{array}{l}\text { Near to flyover surrounded by commercial complex. In the evening } \\
\text { traffic increases. }\end{array}$ & High & Commercial \\
\hline
\end{tabular}

\subsection{Methods}

\subsubsection{Particulate matter $\left(\mathbf{P M}_{10}\right)$}

The 24 hours desiccated filter papers (Whatman filter 8 X 10 in) were pre-weighted on the balance with $0.00001 \mathrm{~g}$ sensitivity. To avoid the contamination the conditioned and weighted filter papers were taken to the field in close envelops for sampling. Particulate matter $\left(\mathrm{PM}_{10}\right)$ sampling was done at flow rate of $1.1 \mathrm{~m}^{3} / \mathrm{min} \mathrm{on}$ High Volume Sampler for 24 hours. Before starting sampling, initial volume, timer, and manometer reading were recorded. After ensuring sampler was properly screwed, filter paper was loaded and sampler was started. Air is drawn through a size-selective inlet and through a filter at a flow rate, which is typically $1.1 \mathrm{~m}^{3} / \mathrm{min}$. Particles with aerodynamic diameter less than the cut-point of the inlet are collected, by the filter. After sampling loaded filter paper was removed and placed in enveloped. Loaded filter paper was again weighted to determine $\mathrm{PM}_{10}$ concentration.

\subsubsection{Sulphur dioxide}

According to "West and Geake" method the sulphur dioxide concentration were determined at the impingent rate above $1 \mathrm{~m}^{3} / \mathrm{min}$ but not more than $2.2 \mathrm{~m} / \mathrm{min}$. Sulphur dioxide from air is absorbed in a solution of potassium tetrachloromercurate (TCM). A dichlorosulphitomercurate complex, which resists oxidation by the oxygen in the air, is formed. Once formed, this complex is stable to strong oxidants such as ozone and oxides of nitrogen and therefore, the absorber solution may be stored for some time prior to analysis. The complex is made to react with para-rosaniline and formaldehyde to form the intensely coloured pararosaniline methylsulphonic acid. The absorbance of the solution is measured by means of $560 \mathrm{~nm}$

\subsubsection{Nitrogen dioxide}

According to " Modified Jacob and Hochheiser method" method the sulphur dioxide concentration were determined at the impingent rate above $1 \mathrm{~m}^{3} / \mathrm{min}$ but not more than $2.2 \mathrm{~m}^{3} / \mathrm{min}$. Ambient nitrogen dioxide $\left(\mathrm{NO}_{2}\right)$ is collected by bubbling air through a solution of sodium hydroxide and sodium arsenite. The concentration of nitrite ion $\left(\mathrm{NO}_{2}\right)$ produced during sampling is determined colorimetrically by reacting the nitrite ion with phosphoric acid, sulfanilamide, and $\mathrm{N}$-(1-naphthyl)-ethylenediamine dihydrochloride (NEDA) and measuring the absorbance of the highly coloured azo-dye at $540 \mathrm{~nm}$. Attachment of dust sampler and gaseous pollutant is as shown in Figure.2. 


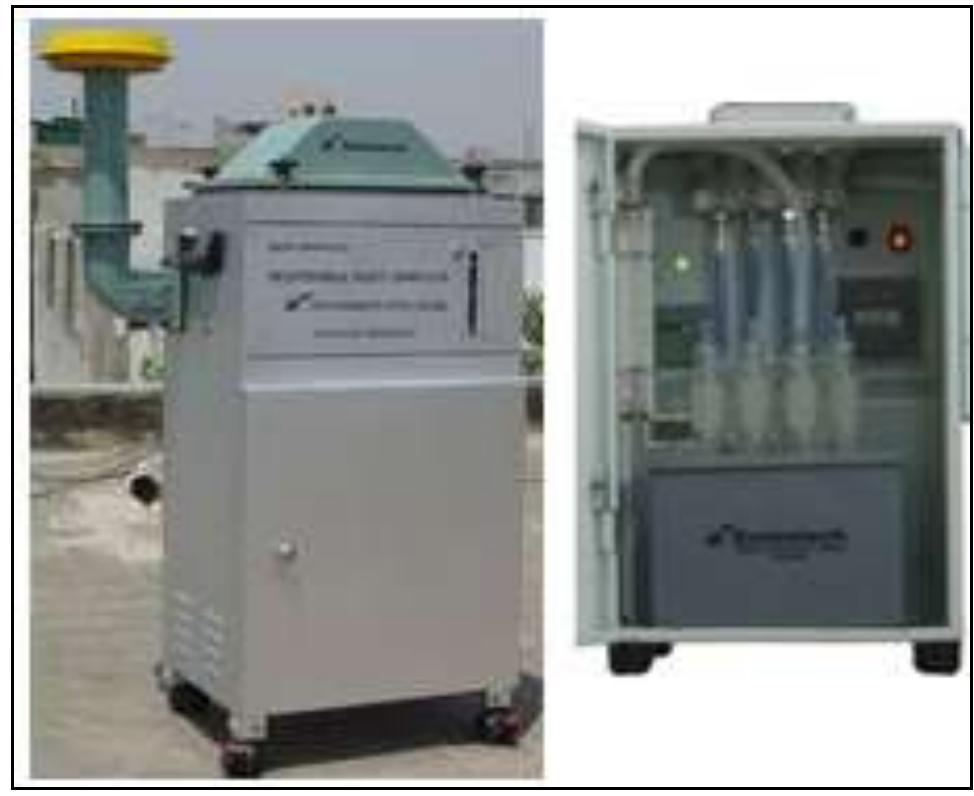

Figure No. 2- Dust sampler with gaseous attachment

\section{Result And Discussion}

Monitoring of particulate matter $\left(\mathrm{PM}_{10}\right)$ and gaseous pollutant $\left(\mathrm{SO}_{2}\right.$ and $\left.\mathrm{NO}_{2}\right)$ has been carried out from May,2016-June,2016 at different locations. Results are compared with permissible limits given by Central Pollution Control Board of India [The Gazette of India, Part III-Section4] as shown in Table 2.

Table 2: National Ambient Air Quality Standards

\begin{tabular}{|c|c|c|c|c|}
\hline Sr.No & Pollutants & Time weighted & \multicolumn{2}{|c|}{ Concentration in ambient air } \\
\cline { 4 - 5 } & & & $\begin{array}{c}\text { Industrial } \\
\text { average } \\
\text { and Ontial, Rural }\end{array}$ & $\begin{array}{c}\text { Ecologically sensitive } \\
\text { area (notified by Central } \\
\text { Govt.) }\end{array}$ \\
\hline 1 & Sulphur Dioxide $\left(\mathrm{SO}_{2}\right)\left(\mu \mathrm{g} / \mathrm{m}^{3}\right)$ & 24 hours & 80 & 80 \\
\hline 2 & Nitrogen Dioxide $\left(\mathrm{NO}_{2}\right)\left(\mu \mathrm{g} / \mathrm{m}^{3}\right)$ & 24 hours & 80 & 80 \\
\hline 3 & Particulate Matter $\left(\mathrm{PM}_{10}\right)\left(\mu \mathrm{g} / \mathrm{m}^{3}\right)$ & 24 hours & 100 & 100 \\
\hline
\end{tabular}

Sulphur dioxide: Concentration of sulphur dioxide ranges from $9.08 \mu \mathrm{g} / \mathrm{m}^{3}$ at Arif colony to $69.91 \mu \mathrm{g} / \mathrm{m}^{3}$ at Chikalthana MIDC as shown in Figure 3.Concentration of sulphur dioxide at all the location is within permissible limits. Concentration of sulphur dioxide at Chikalthana MIDC is just reaching to the permissible limits given by Central Pollution Control Board of India It is highest concentration among all the locations. It might be because on continues burning of coal.

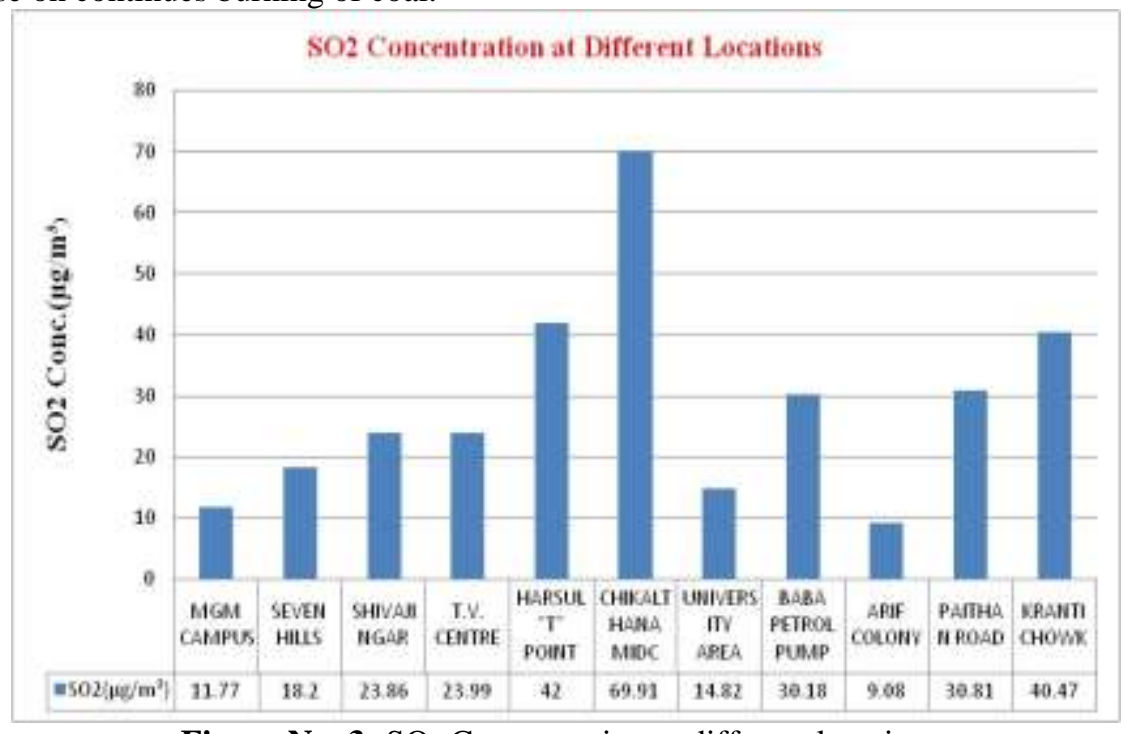

Figure No. 3- $\mathrm{SO}_{2}$ Concentration at different locations. 
Concentration of nitrogen dioxide ranges from $19.68 \mu \mathrm{g} / \mathrm{m}^{3}$ at Arif colony to $72.85 \mu \mathrm{g} / \mathrm{m}^{3}$ at Harsul T-point as shown in Figure 4. At Harsul T-point concentration is more than all other locations. The second highest concentration was found at Kranti chowk. It might because of the emission from heavy vehicular traffic. Minimum value of nitrogen dioxide was found $19.68 \mu \mathrm{g} / \mathrm{m}^{3}$ at Arif colony, it may be because of residential area surrounded by greenery and its high elevation as compare to other locations. Still values of nitrogen dioxide at all the locations are within the permissible limits given by Central Pollution Control Board of India of India.

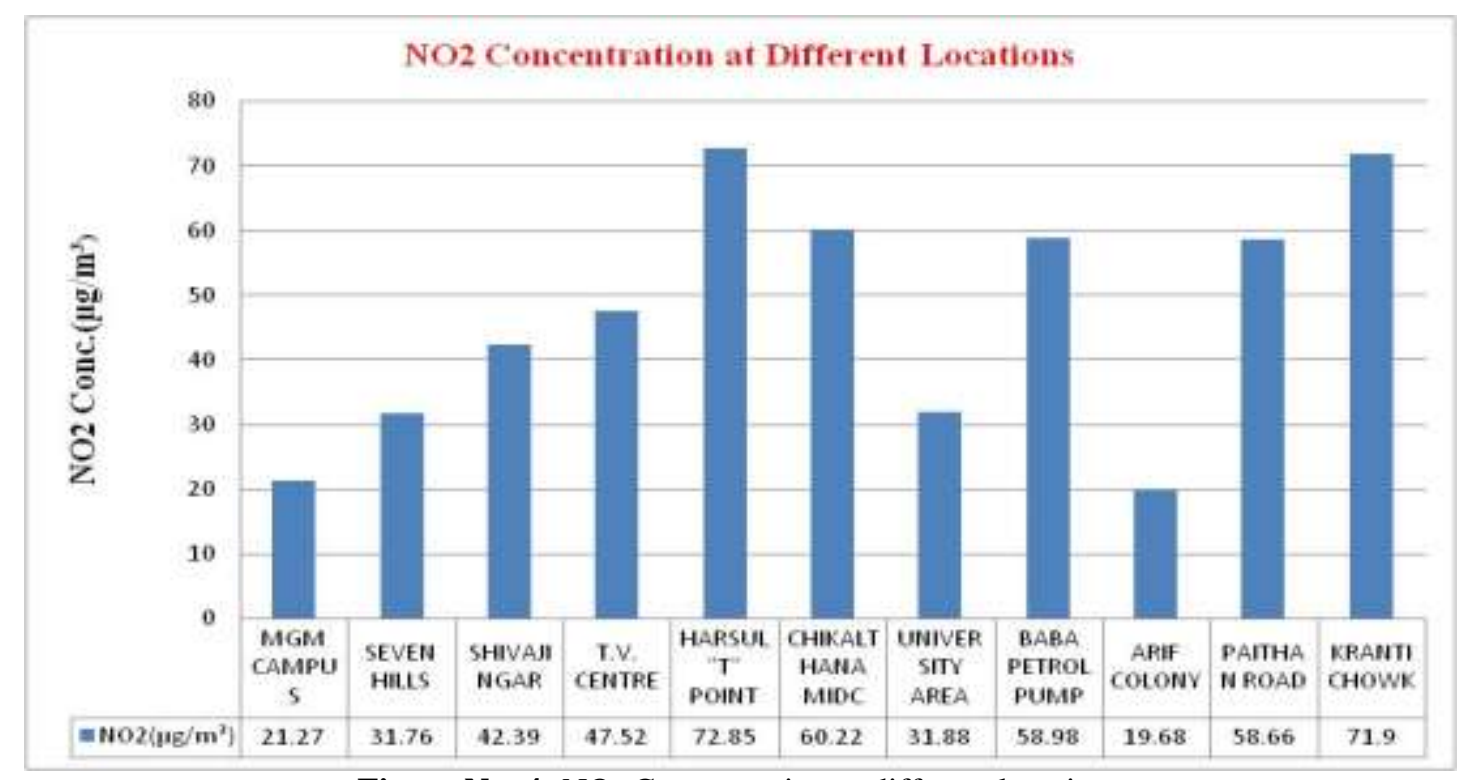

Figure No. 4- $\mathrm{NO}_{2}$ Concentration at different locations

Particulate matter $\left(\mathbf{P M}_{10}\right)$ : Concentration of particulate matter ranges from $99.70 \mu \mathrm{g} / \mathrm{m}^{3}$ at MGM campus to $398.28 \mu \mathrm{g} / \mathrm{m}^{3}$ at Harsul T-point as shown in Figure 5. This is most concern parameter, concentrations were found to be much higher than permissible limits given by Central Pollution Control Board of India. Poor roads, pot holes, draught, less greenery, houses and commercial places located close to the roads and high traffic density might be the reasons of high concentration of particulate matter. Open carrier of construction and demolition material is also one of reason of high concentration. Also uncovered land might be the reason for increasing concentration. In present monitoring it was found that Harsul T-point has highest concentration of particulate matter.

Though the concentration of sulphur dioxide and nitrogen dioxide is within the permissible limits but concentration comparing previous year data is rapidly increasing. This rapidly increasing concentration will have adverse effect on next generation. Hence strategies have to be adopted for combating the menace of air pollution. Otherwise like particulate matter, gaseous pollutant will cross the permissible limits and will produced adverse condition for city.

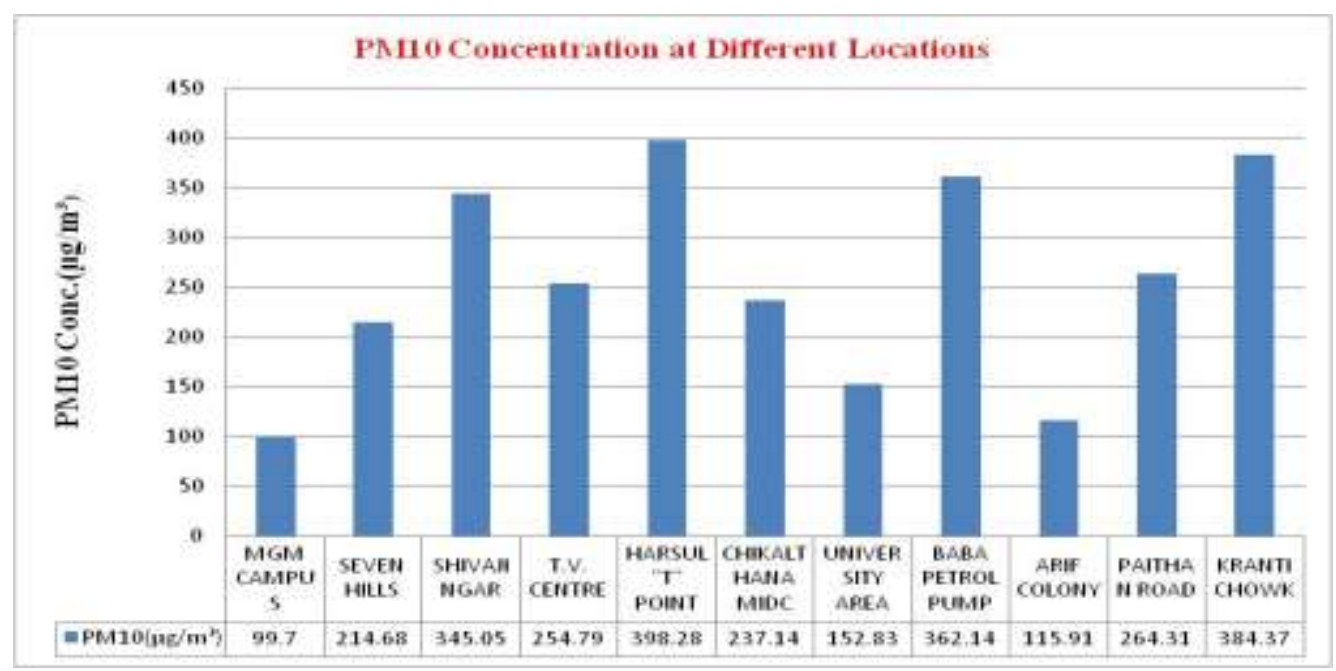

Figure No. 5 - $\mathrm{PM}_{10}$ Concentration at different locations 


\section{Conclusion}

Based on the present study which was carried out to measure the concentration of particulate matter $\left(\mathrm{PM}_{10}\right)$ and gaseous pollutant $\left(\mathrm{SO}_{2}\right.$ and $\left.\mathrm{NO}_{2}\right)$ at different locations in Aurangabad city, the following conclusion can be made.

1) The highest concentration of $\mathrm{SO}_{2}$ was $69.9 \mu \mathrm{g} / \mathrm{m}^{3}$ at Chikalthana MIDC, which is within the permissible limit given by Central Pollution Control Board of India $\left(80 \mu \mathrm{g} / \mathrm{m}^{3}\right)$.

2) The highest concentration of $\mathrm{NO}_{2}$ was $72.85 \mu \mathrm{g} / \mathrm{m}^{3}$ at Harsul T-point which is within the permissible limit given by Central Pollution Control Board of India $\left(80 \mu \mathrm{g} / \mathrm{m}^{3}\right)$.

3) Concentration of particulate matter $\left(\mathrm{PM}_{10}\right)$ was found to be very high which ranges from $99.70 \mu \mathrm{g} / \mathrm{m}^{3}$ at MGM campus to $398.28 \mu \mathrm{g} / \mathrm{m}^{3}$ at Harsul T-point in comparison to permissible limits given by Central Pollution Control Board of India $\left(100 \mu \mathrm{g} / \mathrm{m}^{3}\right)$.

Following control measures can be adopted in order to decrease the concentration of particulate matter and gaseous pollutant.

a) Improving the condition of roads, buses and grass should be planted to avoid air pollution. All the area should be covered with roads, paving blocks or grass

b) Open carrier carrying construction and demolition material should be banned within the city.

c) Motivate the people to use public transport system.

d) Vehicles older than 15 years should be taken off the road.

e) Overloading of vehicles should be avoided

f) CNG should be promoted in the city.

g) Plantation program should be carried out in the city.

h) Provision of water fountain at each junction of roads.

i) Emissions from the vehicles should be checked regularly.

j) Roads should be cleaned periodically by advance road cleaner machine.

\section{References}

[1] Dr.Sohail Ayub and Kashif Baig. Monitoring the influence of outdoor vehicular pollutants concentration on indoor air quality of the houses located close to urban roadway/highways,European International Journal of Science and Technology, Vol 2 No 3,(2013):170-180

[2] Naik Shrikanta. Studies on pollution status of Bondamunda area of Rourkela industrial complex, (2005).

[3] Ahmed Haytham A. Air Quality in Egypt August 1999, Air Quality Monthly Report, Monthly report, August 1999.

[4] Marilena Kampa, Elias Castanas. Human health effects of air pollution. Science direct,151,(2008): 362-367

[5] G.Robin, S.Sankaran. A Study On Ambient Air Quality Monitoring In Chidambara, International Research Journal of Engineering and Technology (IRJET) Vol.03 (2016):2616-2619.

[6] Lomate Varsha U. Studies on Air quality of Maharashtra, India, International Research Journal of Environment Sciences ISSN 2319-1414, Vol4(10), October (2015):30-33

[7] Andre Nel. Air Pollution-Related Illness: Effect of Particles, Science AAAS,Science 308,804(2005):804-806

[8] U.N. Environment Program and WHO Report, Environment,4(March1994):36

[9] Rakesh Kumar and Abba Elizabeth Joseph. Air Pollution Concentrations Of PM2.5, PM10 and NO2 at Ambient and Kerbsite and Their Correlation in Metro City-Mumbai, Environmental Monitoring and Assessment (2006):191-199

[10] Jonathan O. Anderson. Josef G.Thundiyil. Andrew Stolbach. Clearing the Air: A Review of the effects of particulate Matter Air Pollution on Human Health,(2012)8:166-175

[11] Prabhat Kumar Rai. Multifactored health impact of Particulate Matter (PM) and its management: An overview,Environment Skeptics and Critics,(2015),4(1):1-26

[12] National Academy of Sciences, National Research Council, Research Priorities for Airborne Particulate Matter: I-Immediate Priorities and a Long-Range Research Portfolio (National Academy of Sciences, Washington, DC, 1998)

[13] Bhosale, B.J., Late, A., Nalawade, P.M., Chavan, S.P. and Mule, M.B., Studies on assessment of traffic noise level in Aurangabad city, India. Noise Health, (2010) 12(48), 195-198. 